\title{
Effects of Obesity and Smoking on Survival in Non-Small Cell Lung Cancer
}

\author{
Damien M. Hansra1", Tulay Koru-Sengul2, Wei Zhao², Feng Miao², Alicia P. Monedero², \\ Stacey L. Tannenbaum², David J. Lee ${ }^{2}$, Judith Hurley', Margaret M. Byrne ${ }^{2}$ \\ ${ }^{1}$ University of Miami/Jackson Memorial Hospital, Miami, FL, USA \\ ${ }^{2}$ Department of Public Health Sciences and Sylvester Comprehensive Cancer Center of University of Miami \\ Miller School of Medicine, Miami, FL, USA \\ Email: *dmhansra@gmail.com
}

Received 7 February 2016; accepted 21 May 2016; published 24 May 2016

Copyright (C) 2016 by authors and Scientific Research Publishing Inc.

This work is licensed under the Creative Commons Attribution International License (CC BY). http://creativecommons.org/licenses/by/4.0/

c) (i) Open Access

\section{Abstract}

Background: Obesity is an emerging leading cause of morbidity and mortality in the US and the relationship between obesity, tobacco, and survival in NSCLC is unclear. Methods: Data $(n=87,631)$ were obtained from linkage of the 1996-2007 Florida Cancer Data System to the Agency for Health Care Administration database providing procedure and diagnoses codes. Survival time was calculated from date of diagnosis to date of death. Smoking status was categorized as never, current, and former. Obesity (yes/no) = ICD9 code BMI $>30 \mathrm{~kg} / \mathrm{m}^{2}$, cachexia = ICD9 code "wasting syndrome", \& non-obese = non-obese $\&$ non cachectic. Cox proportional regression models used to predict survival; demographic, clinical, treatment factors, \& comorbidities were included in adjusted models with smoking status and obesity as the main factors. Results: The majority of patients (pts) were either former (49\%) or current (40\%) smokers, \& non-obese $(88 \%) .6 .8 \%$ of pts were obese $\& 4.8 \%$ of pts were cachectic. There were significant differences between survival curves and median survival (months) for obese vs. non-obese vs. cachectic pts. (20 vs 10 vs. 7.9; P < 0.001). Former and current smokers had shorter median survival than never smokers $(10.8 \& 9.2$ vs. 11.9; $P<0.001)$. Survival rates (\%) at 1 -yr (60.1 vs. 45.2 vs. 37.7; $P<0.001)$, 5 -yr (30.3 vs. 15.4 vs. 9.5; $P<0.001), 10$-yr $(18.1$ vs. 7.6 vs. $2.7 ; P<0.001)$ were better for obese vs. non-obese and cachectic pts respectively. Independent predictor of worse survival in the unadjusted model was former (HR 1.08; $P<0.001$ ) and current (HR 1.20; $P<0.001$ ) smokers compared to never. Obese and non-obese pts had better survival vs. cachexia pts. (HR 0.52; $P<0.001$ and HR 0.80, $p<0.001$ respectively) and obese had better survival than Non-obese pts (HR $0.65, p<0.001$ ). In the adjusted model, controlling for extensive variables and comorbidities, former (HR 1.11; $P<0.001)$ and current (HR 1.19; $P<0.001$ ) smokers still had significantly worse survival vs. never smokers. Obese patients still had better survival (HR 0.87; $P<0.001$, and HR $0.88, p<0.001$ ) vs. cachexia patients and non-obese respectively, survival rate was not significantly different compare non-

\footnotetext{
${ }^{*}$ Corresponding author.
} 
obese with cachexia. Conclusions: Our results show that being a former or current smoker worsens survival while obesity improved survival when compared with cachexia patients or Non-obese.

\title{
Keywords
}

\author{
Lung Cancer, Non-Small Cell Lung Cancer, Tobacco, Smoking, Obesity
}

\section{Introduction}

Tobacco, the leading cause of preventable death in the United States (US), has been linked to the development of many cancers, most notably lung cancer [1]. Other risk factors for lung cancer have been explored in the literature: radon gas [2], asbestos exposure [3], high-dose beta carotene [4], low dietary consumption of fruits and vegetables [5], and obesity [6]. Smoking not only increases the risk of developing lung cancer but is also associated with decreased survival after diagnosis [7]. Although obesity is a major cause of morbidity and mortality in the US, the impact of obesity on lung cancer survival is unclear. Furthermore, the interrelationship between obesity, tobacco, and survival time after diagnosis for patients with non-small cell lung cancer (NSCLC) is uncertain. We examined BMI and smoking as predictors of survival in patients with NSCLC using a populationbased cancer registry in the state of Florida.

\section{Methods}

After institutional review board approval, data were obtained from linkage of the 1996-2007 Florida Cancer Data System (FCDS), a population-based cancer registry, to the Agency for Health Care Administration (AHCA) database which provides procedure and diagnoses codes, and the US census. We followed this cohort for an additional 3 years to allow for a determination of survival status through the year 2010.

\subsection{Sample}

Inclusion criteria were all adult patients 18 years or older diagnosed with NSCLC from 1996-2007 and residing in the state of Florida during 1996-2007 $(n=106,824)$. Exclusion criteria were patients with missing values on age of diagnosis, county of diagnosis, survival time, race, ethnicity, socioeconomic status (SES), smoking history, and obesity. Also, patients with carcinoma in situ were excluded. A total of 19,193 patients were excluded and 87,631 patients met full inclusion criteria.

\subsection{Variables}

Overall survival (OS) was defined as the time from diagnosis to death (information found in the FCDS database) from any cause with surviving patients censored at the date of last contact. Self-reported smoking status was categorized as never, current, and former. Obesity (yes/no) was determined by presence of an ICD9 diagnosis code for obesity indicating body mass index (BMI) of $\geq 30$. Cachexia was determined by presence of ICD 9 diagnosis code for "wasting syndrome". Non-obese patients were all non-obese and non-cachectic patients.

Sociodemographic variables for patients in our data included: race (Black, White, or Other), ethnicity (Hispanic/non-Hispanic), SES (derived from the US census using percent of households in a census tract living below the federal poverty line and categorized as lowest $[\geq 20 \%$ below poverty line], middle low $[<20$ and $>10 \%]$, middle high $[\geq 5$ and $\leq 10 \%]$, highest $[<5 \%]$ ), age at diagnosis, sex, marital status (married, never married, divorced/widowed/separated), treating facility type (academic vs. non-academic), treating hospital volume (low vs. high), insurance status (uninsured, private, Medicaid, Medicare, veteran/military).

Pathological and clinical characteristics included: number of co-morbid conditions (none, 1 - 2, 3 - 4, >4), Surveillance Epidemiology and End Results (SEER) stage at diagnosis (localized, regional with direct extension +/- lymph nodes, regional with lymph nodes only, distant, unknown/unstaged), grade (undifferentiated, poorly-differentiated, moderately-differentiated, well-differentiated, unknown), histologic type (adenocarcinoma, squamous cell carcinoma/combined complex, neuroendocrine, large cell and other), treatments of chemotherapy, 
radiation therapy, and surgery (yes/no/unknown).

\subsection{Statistical Analysis}

Descriptive statistics of the demographic, pathological, and clinical characteristics were calculated for the overall sample as well as by smoking status and obesity status. Frequencies and percentages are shown for categorical variables and means, standard deviations, medians, first and the third quintiles for the continuous variables. The overall survival rates at 1-, 3-, 5-, and 10-years were calculated for the whole population, by smoking status, by presence of obesity status, and by smoking status $\mathrm{x}$ obesity status. Median overall survival was estimated and survival curves were plotted using the Kaplan-Meier methodology. Log-rank tests were used for the survival plots to compare overall survival by smoking status, and obesity status.

Cox proportional hazards regression models were used to determine the effect of potential factors on OS. Unadjusted and adjusted hazard ratios (HR), 95\% confidence intervals (95\% CI) and p-values were calculated from these models. We first performed univariate Cox regression to examine the association of OS with smoking, obesitystatus, and other factors such as race, ethnicity, and SES, respectively. Multivariate Cox regression models were then performed with the main predictors of smoking status and obesity. We adjusted for potential confounding variables using the sociodemographic variables in Table 1, the clinical characteristic variables in Table 2,

Table 1. Demographic characteristics of lung cancer stratified by smoking status and obesity status (column \%).

\begin{tabular}{|c|c|c|c|c|c|c|c|c|c|c|c|c|c|c|}
\hline \multirow{3}{*}{ Variable } & \multirow{2}{*}{\multicolumn{2}{|c|}{ Total patients }} & \multicolumn{6}{|c|}{ Tobacco use } & \multicolumn{6}{|c|}{ Obesity } \\
\hline & & & \multicolumn{2}{|c|}{ Never } & \multicolumn{2}{|c|}{ History } & \multicolumn{2}{|c|}{ Current } & \multicolumn{2}{|c|}{ Cachexia } & \multicolumn{2}{|c|}{ Non-obese } & \multicolumn{2}{|c|}{ Obese } \\
\hline & $\mathrm{n}$ & $\%$ & $\mathrm{n}$ & $\%$ & $\mathrm{n}$ & $\%$ & $\mathrm{n}$ & $\%$ & $\mathrm{n}$ & $\%$ & $\mathrm{n}$ & $\%$ & $\mathrm{n}$ & $\%$ \\
\hline Total patients & 87,631 & 100.0 & 9326 & 100.0 & 43,270 & 100.0 & 35,035 & 100.0 & 4175 & 100.0 & 77,526 & 100.0 & 5930 & 100.0 \\
\hline \multicolumn{15}{|l|}{ Tobacco use } \\
\hline Never smoke & 9326 & 10.6 & 9326 & 100.0 & - & - & - & - & 290 & 6.9 & 8308 & 10.7 & 728 & 12.3 \\
\hline History smoke & 43,270 & 49.4 & - & - & 43,270 & 100.0 & - & - & 1611 & 38.6 & 38,350 & 49.5 & 3309 & 55.8 \\
\hline Current smoke & 35,035 & 40.0 & - & - & - & - & 35,035 & 100.0 & 2274 & 54.5 & 30,868 & 39.8 & 1893 & 31.9 \\
\hline \multicolumn{15}{|l|}{ Obesity } \\
\hline Cachexia & 4175 & 4.8 & 290 & 3.1 & 1611 & 3.7 & 2274 & 6.5 & 4175 & 100.0 & - & - & - & - \\
\hline Non-obese & 77,526 & 88.5 & 8308 & 89.1 & 38,350 & 88.6 & 30,868 & 88.1 & - & - & 77,526 & 100.0 & - & - \\
\hline Obese & 5930 & 6.8 & 728 & 7.8 & 3,309 & 7.6 & 1893 & 5.4 & - & - & - & - & 5930 & 100.0 \\
\hline \multicolumn{15}{|l|}{ Race } \\
\hline White & 80,480 & 91.8 & 8336 & 89.4 & 40,571 & 93.8 & 31,573 & 90.1 & 3472 & 83.2 & 71,586 & 92.3 & 5422 & 91.4 \\
\hline Black & 6492 & 7.4 & 792 & 8.5 & 2425 & 5.6 & 3275 & 9.3 & 668 & 16.0 & 5335 & 6.9 & 489 & 8.2 \\
\hline Other & 659 & 0.8 & 198 & 2.1 & 274 & 0.6 & 187 & 0.5 & 35 & 0.8 & 605 & 0.8 & 19 & 0.3 \\
\hline \multicolumn{15}{|l|}{ Hispanic origin } \\
\hline Non-hispanic & 82,377 & 94.0 & 8372 & 89.8 & 41,096 & 95.0 & 32,909 & 93.9 & 3912 & 93.7 & 72,911 & 94.0 & 5554 & 93.7 \\
\hline Hispanic & 5254 & 6.0 & 954 & 10.2 & 2174 & 5.0 & 2126 & 6.1 & 263 & 6.3 & 4,615 & 6.0 & 376 & 6.3 \\
\hline \multicolumn{15}{|c|}{ Age at diagnosis (yrs) } \\
\hline Mean & \multicolumn{2}{|c|}{68.9} & \multicolumn{2}{|c|}{71.1} & \multicolumn{2}{|c|}{71.6} & \multicolumn{2}{|c|}{64.9} & \multicolumn{2}{|c|}{66.9} & \multirow{2}{*}{\multicolumn{2}{|c|}{$\begin{array}{l}69.1 \\
10.9\end{array}$}} & \multicolumn{2}{|c|}{67.7} \\
\hline STD & \multicolumn{2}{|c|}{10.9} & \multicolumn{2}{|c|}{12.5} & \multicolumn{2}{|c|}{9.6} & \multicolumn{2}{|c|}{10.7} & \multicolumn{2}{|c|}{11.4} & & & \multicolumn{2}{|c|}{10.0} \\
\hline Median & 70 & & & 3.0 & 73 & & 66 & & & 3.0 & 70 & & & .0 \\
\hline Q1, Q3 & 62.0 & 77.0 & 64.0 & 80.0 & 66.0 & 78.0 & 58.0 & 73.0 & 59.0 & 76.0 & 62.0 & 77.0 & 61.0 & 75.0 \\
\hline Min, Max & 18.0 & 104.0 & 18.0 & 102.0 & 20.0 & 104.0 & 22.0 & 102.0 & 21.0 & 98.0 & 18.0 & 104.0 & 22.0 & 96.0 \\
\hline Sex & & & & & & & & & & & & & & \\
\hline Female & 38,445 & 43.9 & 5801 & 62.2 & 17,648 & 40.8 & 14,996 & 42.8 & 1517 & 36.3 & 33,889 & 43.7 & 3039 & 51.2 \\
\hline Male & 49,186 & 56.1 & 3525 & 37.8 & 25,622 & 59.2 & 20,039 & 57.2 & 2658 & 63.7 & 43,637 & 56.3 & 2891 & 48.8 \\
\hline
\end{tabular}


Table 2. Pathological and clinical characteristics (column \%).

\begin{tabular}{|c|c|c|c|c|c|c|c|c|c|c|c|c|c|c|}
\hline \multirow{3}{*}{ Variable } & \multirow{2}{*}{\multicolumn{2}{|c|}{ Total patients }} & \multicolumn{6}{|c|}{ Tobacco use } & \multicolumn{6}{|c|}{ Obesity } \\
\hline & & & \multicolumn{2}{|c|}{ Never smoke } & \multicolumn{2}{|c|}{$\begin{array}{l}\text { History } \\
\text { smoke }\end{array}$} & \multicolumn{2}{|c|}{$\begin{array}{l}\text { Current } \\
\text { smoke }\end{array}$} & \multicolumn{2}{|c|}{ Cachexia } & \multicolumn{2}{|c|}{ Non-obese } & \multicolumn{2}{|c|}{ Obese } \\
\hline & $\mathrm{n}$ & $\%$ & $\mathrm{n}$ & $\%$ & $\mathrm{n}$ & $\%$ & $\mathrm{n}$ & $\%$ & $\mathrm{n}$ & $\%$ & $\mathrm{n}$ & $\%$ & $\mathrm{n}$ & $\%$ \\
\hline Total patients & 87,631 & 100.0 & 9,326 & 100.0 & 43,270 & 100.0 & 35,035 & 100.0 & 4,175 & 100.0 & 77,526 & 100.0 & 5930 & 100.0 \\
\hline \multicolumn{15}{|l|}{ Co-morbidity } \\
\hline None & 4213 & 4.8 & 574 & 6.2 & 1874 & 4.3 & 1765 & 5.0 & - & - & 4213 & 5.4 & - & - \\
\hline $1-2$ & 2594 & 3.0 & 411 & 4.4 & 1155 & 2.7 & 1028 & 2.9 & 2 & 0.0 & 2585 & 3.3 & 7 & 0.1 \\
\hline $3-4$ & 6530 & 7.5 & 954 & 10.2 & 3001 & 6.9 & 2575 & 7.3 & 52 & 1.2 & 6412 & 8.3 & 66 & 1.1 \\
\hline$>4$ & 74,294 & 84.8 & 7387 & 79.2 & 37,240 & 86.1 & 29,667 & 84.7 & 4121 & 98.7 & 64,316 & 83.0 & 5857 & 98.8 \\
\hline \multicolumn{15}{|l|}{ SEER stage } \\
\hline Localized & 19,546 & 22.3 & 2,278 & 24.4 & 10,253 & 23.7 & 7015 & 20.0 & 715 & 17.1 & 16,964 & 21.9 & 1867 & 31.5 \\
\hline $\begin{array}{l}\text { Regional, direct extension } \\
\pm \text { lymph nodes }\end{array}$ & 13,140 & 15.0 & 1074 & 11.5 & 6613 & 15.3 & 5453 & 15.6 & 625 & 15.0 & 11,635 & 15.0 & 880 & 14.8 \\
\hline $\begin{array}{c}\text { Regional, lymph nodes } \\
\text { only }\end{array}$ & 9123 & 10.4 & 801 & 8.6 & 4655 & 10.8 & 3667 & 10.5 & 366 & 8.8 & 8064 & 10.4 & 693 & 11.7 \\
\hline Distant & 35,917 & 41.0 & 3824 & 41.0 & 16,688 & 38.6 & 15,405 & 44.0 & 1973 & 47.3 & 32,061 & 41.4 & 1883 & 31.8 \\
\hline Unknown/Unstaged & 9905 & 11.3 & 1349 & 14.5 & 5061 & 11.7 & 3495 & 10.0 & 496 & 11.9 & 8802 & 11.4 & 607 & 10.2 \\
\hline \multicolumn{15}{|l|}{ Grade } \\
\hline Undifferentiated & 2822 & 3.2 & 206 & 2.2 & 1,295 & 3.0 & 1321 & 3.8 & 151 & 3.6 & 2538 & 3.3 & 133 & 2.2 \\
\hline Poorly-differentiated & 27,782 & 31.7 & 2,186 & 23.4 & 13,320 & 30.8 & 12,276 & 35.0 & 1368 & 32.8 & 24,683 & 31.8 & 1731 & 29.2 \\
\hline Moderately-differentiated & 15,981 & 18.2 & 1539 & 16.5 & 8299 & 19.2 & 6,143 & 17.5 & 681 & 16.3 & 14,094 & 18.2 & 1206 & 20.3 \\
\hline Well-differentiated & 4437 & 5.1 & 814 & 8.7 & 2308 & 5.3 & 1315 & 3.8 & 159 & 3.8 & 3904 & 5.0 & 374 & 6.3 \\
\hline Unknown/not stated & 36,609 & 41.8 & 4581 & 49.1 & 18,048 & 41.7 & 13,980 & 39.9 & 1816 & 43.5 & 32,307 & 41.7 & 2486 & 41.9 \\
\hline \multicolumn{15}{|l|}{ Regional Nodes Positive } \\
\hline No & 16,169 & 18.5 & 1,656 & 17.8 & 8400 & 19.4 & 6,113 & 17.4 & 523 & 12.5 & 14,101 & 18.2 & 1545 & 26.1 \\
\hline Yes & 8568 & 9.8 & 816 & 8.7 & 4348 & 10.0 & 3404 & 9.7 & 295 & 7.1 & 7663 & 9.9 & 610 & 10.3 \\
\hline Unknown & 62,894 & 71.8 & 6854 & 73.5 & 30,522 & 70.5 & 25,518 & 72.8 & 3357 & 80.4 & 55,762 & 71.9 & 3775 & 63.7 \\
\hline \multicolumn{15}{|l|}{ Histology } \\
\hline Adenocarcinoma & 38,684 & 44.1 & 5173 & 55.5 & 19,391 & 44.8 & 14,120 & 40.3 & 1650 & 39.5 & 34,509 & 44.5 & 2525 & 42.6 \\
\hline $\begin{array}{l}\text { Squamous/combine } \\
\text { complex }\end{array}$ & 26,270 & 30.0 & 1675 & 18.0 & 13,080 & 30.2 & 11,515 & 32.9 & 1433 & 34.3 & 23,047 & 29.7 & 1790 & 30.2 \\
\hline Neoendocrine & 2277 & 2.6 & 692 & 7.4 & 910 & 2.1 & 675 & 1.9 & 58 & 1.4 & 1899 & 2.4 & 320 & 5.4 \\
\hline Large cell & 7038 & 8.0 & 608 & 6.5 & 3341 & 7.7 & 3089 & 8.8 & 338 & 8.1 & 6353 & 8.2 & 347 & 5.9 \\
\hline Other & 13,362 & 15.2 & 1178 & 12.6 & 6548 & 15.1 & 5636 & 16.1 & 696 & 16.7 & 11,718 & 15.1 & 948 & 16.0 \\
\hline \multicolumn{15}{|l|}{ Chemotherapy } \\
\hline No & 55,362 & 63.2 & 6407 & 68.7 & 27,483 & 63.5 & 21,472 & 61.3 & 2512 & 60.2 & 49,063 & 63.3 & 3787 & 63.9 \\
\hline Yes & 28,410 & 32.4 & 2544 & 27.3 & 13,976 & 32.3 & 11,890 & 33.9 & 1513 & 36.2 & 25,037 & 32.3 & 1860 & 31.4 \\
\hline Unknown & 3859 & 4.4 & 375 & 4.0 & 1811 & 4.2 & 1673 & 4.8 & 150 & 3.6 & 3426 & 4.4 & 283 & 4.8 \\
\hline \multicolumn{15}{|l|}{ Radiation therapy } \\
\hline No & 47,544 & 54.3 & 6060 & 65.0 & 23,439 & 54.2 & 18,045 & 51.5 & 2086 & 50.0 & 41,883 & 54.0 & 3575 & 60.3 \\
\hline Yes & 38,193 & 43.6 & 3091 & 33.1 & 18,977 & 43.9 & 16,125 & 46.0 & 2002 & 48.0 & 33,937 & 43.8 & 2254 & 38.0 \\
\hline Unknown & 1894 & 2.2 & 175 & 1.9 & 854 & 2.0 & 865 & 2.5 & 87 & 2.1 & 1706 & 2.2 & 101 & 1.7 \\
\hline \multicolumn{15}{|l|}{ Surgery } \\
\hline No & 59,852 & 68.3 & 6304 & 67.6 & 28,936 & 66.9 & 24,612 & 70.2 & 3271 & 78.3 & 53,121 & 68.5 & 3460 & 58.3 \\
\hline Yes & 26,836 & 30.6 & 2900 & 31.1 & 13,894 & 32.1 & 10,042 & 28.7 & 870 & 20.8 & 23,571 & 30.4 & 2395 & 40.4 \\
\hline Unknown & 943 & 1.1 & 122 & 1.3 & 440 & 1.0 & 381 & 1.1 & 34 & 0.8 & 834 & 1.1 & 75 & 1.3 \\
\hline
\end{tabular}


and 31 individual Elixhauser comorbidity conditions entered as yes/no variables. We examined the models for violations of the proportional hazards assumptions, and found no violations. We also found no significant interactions between obesity status and smoking status in the adjusted models. The outcomes of patients treated at individual facilities are not independent, and therefore, we used robust standard errors to adjust for this clustering of patients in facilities. Statistical analyses were conducted using SAS software version 9.3 (SAS Institute Inc, Cary, North Carolina).

\section{Results}

The majority of patients were former (49.4\%) or current (40\%) smokers, and not obese (88.5\%) (Table 1). 6.8\% of patients were obese and $4.8 \%$ of patients were cachectic. The median age at diagnosis was 70 years old with a range of 18 to 104 years old. Most patients were male (56.1\%), White (91.8\%) and non-Hispanic (94\%) patients. The mean age at diagnosis of current smokers was substantially younger (64.9 years) than that of former smokers (71.6 years) or never smokers (71.1 years). A higher percentage of never smokers were female (62.2\%) than male (37.8\%); whereas more current smokers were male (57.2\%) than female (42.8\%).

Table 2 shows clinical characteristics of patients. There was a high rate of comorbidities in this population, with $84.8 \%$ overall having 4 or more comorbidities. The most common comorbidities include congestive heart failure, cardiac arrhythmia, hypertension, diabetes, and depression. More current (84.7\%) and former (86.1\%) smokers had 4 or more comorbidities than did never smokers (79.2\%); and a much higher percentage of obese patients (98.8\%) and cachectic patients $(98.7 \%)$ had 4 or more comorbidities than did non-obese patients (83.0\%). Conversely, obese patients were more likely to be diagnosed with localized disease (31.5\%) than were non-obese patients (21.9\%) and cachectic patients (17.1\%). Also obese patient were less likely to be diagnosed with distant disease (31.8\%) compared with non-obese (41.4\%) and cachectic patients (47.3\%). The majority of patients who never smoked had adenocarcinoma (55.5\%) compared with $44.8 \%$ of former smokers and $40.3 \%$ of current smokers (Table 2). In terms of treatments, $40.4 \%$ obese patients vs. $30.4 \%$ of non-obese patients vs $20.8 \%$ of cachectic patients had surgery (Table 2). $31.4 \%$ of obese patients vs. $32.3 \%$ of non-obese patients vs. $36.2 \%$ of cachectic patients had chemotherapy. $38 \%$ of obese patients had radiation vs. $43.8 \%$ of non-obese patients vs. $48 \%$ of cachectic patients.

The overall median survival time (MST) of patients was 10.2 months (Table 3). Median survival was 20.0 vs. 10.0 vs. 7.9 months for obese vs. non-obese vs. cachectic, respectively $(\mathrm{p}<0.001)$. Survival rates $(\%)$ were better for obese vs. non-obese vs. cachectic patients: 1 -year ( 60.1 vs. 45.2 vs. 37.7 ; p $<0.001$ ), 5-year (30.3 vs. 15.4 vs. $9.5 \mathrm{p}<0.001)$, and 10 -year (18.1 vs. 7.6 vs. $2.7 \mathrm{p}<0.001)$. Median survival times by smoking status were 9.2 (current), 10.8 (former) and 11.9 (never) months (Table 3). Survival rates (\%) were worse for current and former smokers vs. never smokers at 1, 3, 5, and 10 years.

Figure 1 shows Kaplan-Meier survival curves for the entire population, by smoking status, and by obesity status. There are significant differences in overall survival by obesity status, with patients who are obese having significantly better survival than non-obese and cachectic patients (log rank test, $\mathrm{p}<0.001$ ). Also, significant differences in overall survival by smoking status, with survival lowest for current smokers and highest for never smokers (log rank test, $\mathrm{p}<0.001$ ).

Table 3. Median and survival rates, $\mathrm{n}=87,631$.

\begin{tabular}{|c|c|c|c|c|c|}
\hline & \multirow[t]{2}{*}{ Median survival (months) } & \multicolumn{3}{|c|}{$\begin{array}{l}\text { Survival rates (\%) at time (yrs) } \\
\text { after diagnosis }\end{array}$} & \multirow[b]{2}{*}{$10 \mathrm{yrs}$} \\
\hline & & $1 \mathrm{yr}$ & 3 yrs & $5 \mathrm{yrs}$ & \\
\hline Overall & 10.2 & 45.8 & 23.2 & 16.1 & 8.0 \\
\hline \multicolumn{6}{|l|}{ Tobacco use } \\
\hline Never & 11.9 & 49.6 & 27.7 & 20.1 & 10.6 \\
\hline History & 10.8 & 47.2 & 24.2 & 16.8 & 8.3 \\
\hline Current & 9.2 & 43.1 & 20.8 & 14.2 & 6.9 \\
\hline \multicolumn{6}{|l|}{ Obesity } \\
\hline Cachexia & 7.9 & 37.7 & 15.0 & 9.5 & 2.7 \\
\hline Non-obese & 10.0 & 45.2 & 22.5 & 15.4 & 7.6 \\
\hline Obese & 20.0 & 60.1 & 38.6 & 30.3 & 18.1 \\
\hline
\end{tabular}



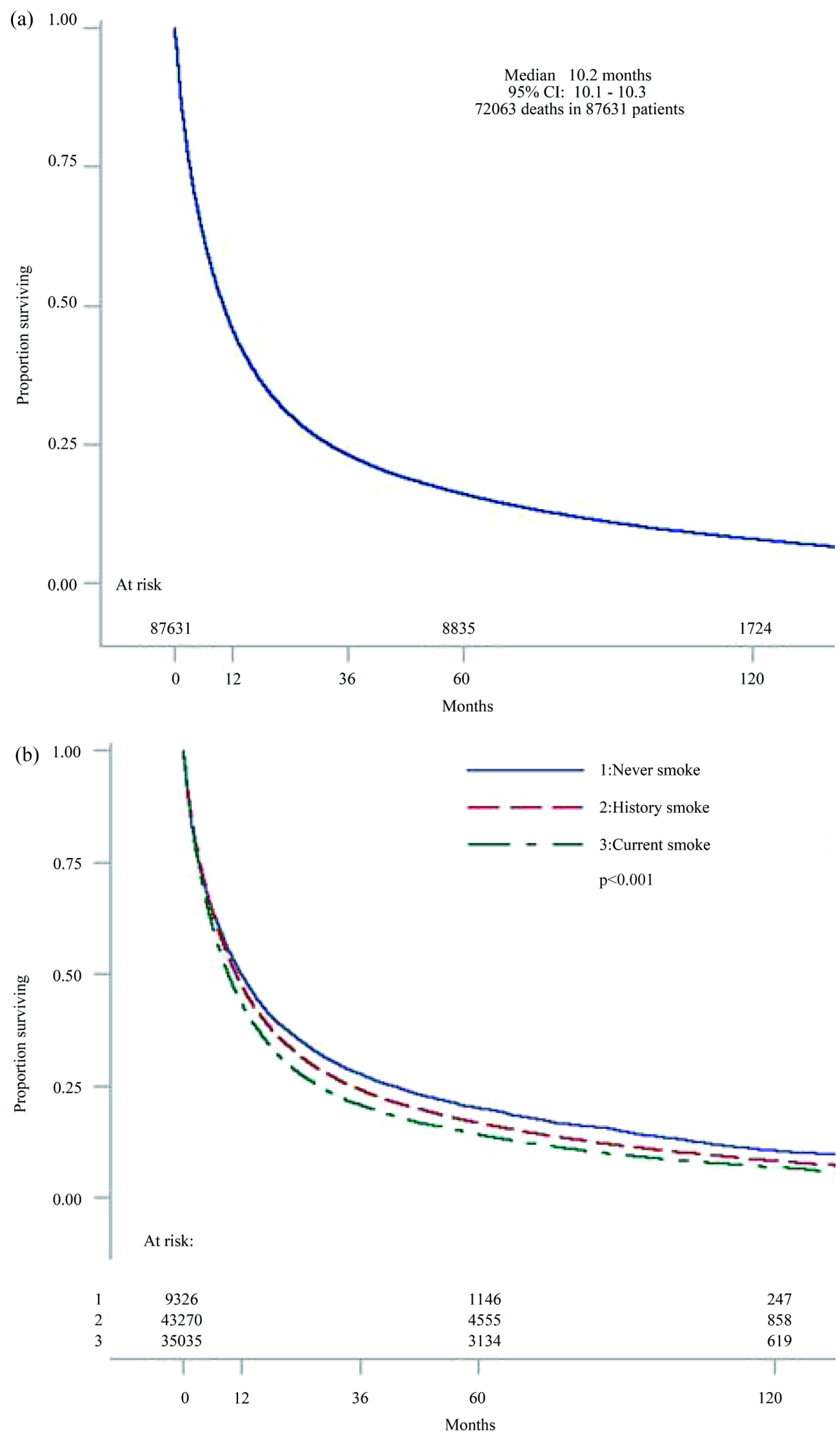

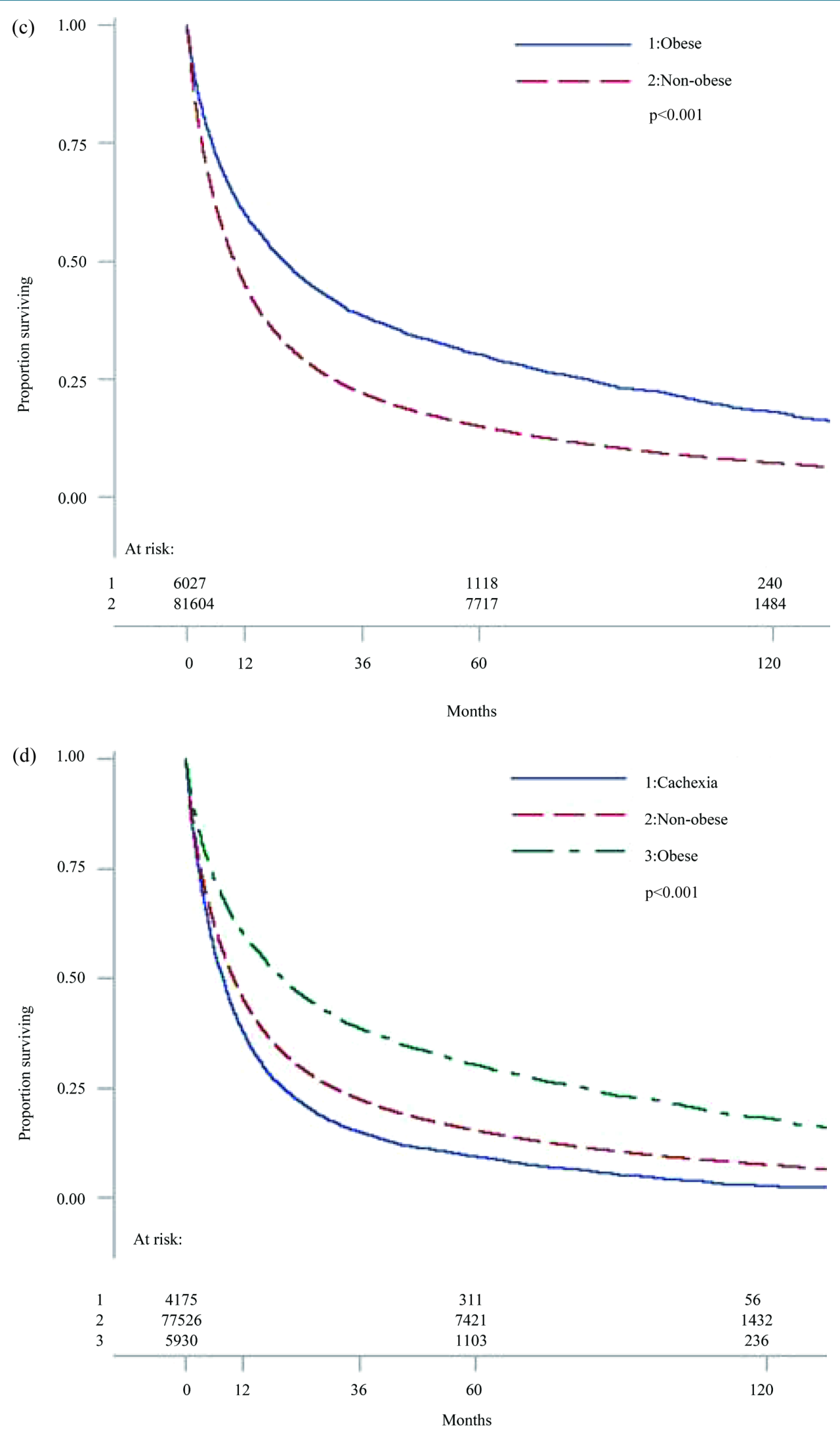

Figure 1. Survival plots. 
Table 4 shows results from the univariate and multivariate Cox regressions. In the univariate model, compared to never smokers, former (HR 1.08; 95\% CI 1.06 - 1.11, P < 0.001) and current smokers (HR 1.20; 95\% CI 1.16 - 1.23, $\mathrm{P}<0.001$ ) had significantly worse survival. Obese and non-obese patients had better survival when compared with cachectic patients (HR 0.52; 95\% CI 0.49 - 0.54, P < 0.001 \& HR 0.80; $95 \%$ CI 0.77 - 0.82 respectively). Furthermore obese patients had better survival compared with non-obese patients (HR 0.65; 95\% CI 0.63 - 0.67). Blacks had significantly worse and patients in higher SES categories had significantly better survival in univariate models.

In the multivariate model, controlling for all confounding variables and individual co-morbidities, former (HR 1.11; 95\% CI 1.08 - 1.14, P < 0.001) and current (HR 1.19; 95\% CI 1.15 - 1.23, P < 0.001) smokers still had significantly worse survival compared with never smokers. Obese patients still maintained better survival (HR 0.87; 95\% CI 0.81 - 0.92, P < 0.001 \& HR 0.88; 95\% CI 0.85 - 0.91 P < 0.001) than non-obese patients. After controlling for demographic and clinical characteristics, Blacks no longer had worse survival than Whites. However, Hispanics now showed significantly better survival compared with non-Hispanics (HR 0.94; 95\% CI 0.88 - 1.00, P < 0.001) and other race had better survival compared to White (HR 0.89; 95\% CI 0.81 - $0.96, \mathrm{P}=$ 0.005). Patients with highest (HR 0.88; 95\% CI 0.84 - 0.91, P < 0.001) and middle-high (HR 0.92; $95 \%$ CI 0.89 0.95, $\mathrm{P}<0.001)$ SES maintained better survival compared with lowest SES.

There were no significant interactions between smoking status and obesity in the adjusted model.

\section{Discussion}

Lung cancer was the most commonly diagnosed cancer as well as the leading cause of cancer death in males in 2008 globally [1]. Among females it was the fourth most commonly diagnosed cancer and the second leading cause of cancer death [1]. In the US, there will be an estimated 228,000 new cases of lung cancer and 159,500 deaths in 2013 [8]. Cigarette smoking has been positively correlated with lung cancer (both small-cell and nonsmall cell) in North America and Europe [3] and has been shown to increase mortality from lung cancer when compared with never-smoking patients [7] [9]. The results of our study confirm this relationship: never smokers had better survival compared with former and current smokers.

The relationship between obesity and NSCLC is not as obvious as that of smoking. While studies show that obesity is a strong risk factor for many cancers including colon, breast, endometrial, stomach, pancreas, gallbladder, and liver cancer [6] [10] [11], there is evidence that obesity may be protective against lung cancer risk [12]-[21]. There are studies, however, that show null [22]-[24], mixed [25] or opposite [26] results for the protective effect of obesity. A meta-analysis by Yang et al. found that excess body weight was inversely associated with incidence of NSCLC [27]. This study, however, was criticized for large heterogeneity of results, lack offormal evaluation of study quality, and confounding by smoking [28].

The association of increased BMI and NSCLC survival is not as well defined in the literature as the data on BMI and risk of developing NSCLC. Calle et al. conducted a prospective cohort analysis of different cancer types including lung cancer patients and concluded that increased body weight was associated with increased death rates for all cancers combined and for cancers at multiple specific sites [6]. In this study there was a significant inverse association between BMI and death from lung cancer in the total populations with greater effect at larger BMI categories. However, these investigators did not separately analyze NSCLC and small-cell lung

Table 4. Cox proportional hazard regression models, $\mathrm{n}=87,631$.

\begin{tabular}{|c|c|c|c|c|c|}
\hline \multirow[b]{2}{*}{ Prognostic factors } & \multirow[b]{2}{*}{ Category } & \multicolumn{2}{|c|}{ Univariate } & \multicolumn{2}{|c|}{ Multivariate } \\
\hline & & HR (95\% CI) & P value & HR (95\% CI) & P value \\
\hline \multirow[t]{3}{*}{ FCDS tobacco use } & Never & 1.00 & & 1.00 & \\
\hline & History & $1.08(1.06,1.11)$ & $<0.001$ & $1.11(1.08,1.14)$ & $<0.001$ \\
\hline & Current & $1.20(1.16,1.23)$ & $<0.001$ & $1.19(1.16,1.23)$ & $<0.001$ \\
\hline \multirow[t]{4}{*}{ Obesity } & Cachexia & 1.00 & & 1.00 & \\
\hline & Non-obese & $0.80(0.77,0.82)$ & $<0.001$ & $0.99(0.94,1.04)$ & 0.548 \\
\hline & Obese & $0.52(0.49,0.54)$ & $<0.001$ & $0.87(0.81,0.92)$ & $<0.001$ \\
\hline & Obese vs. Non-obese (1.00) & $0.65(0.63,0.67)$ & $<0.001$ & $0.88(0.85,0.91)$ & $<0.001$ \\
\hline
\end{tabular}


cancer. [6]. When subgroup analyses were performed on patients who were never smokers, the inverse association was present, but not statistically significant. The lack of significance might be due to the relatively small sample size in that analysis ( $n=156$ males, $n=476$ females). In another study Attaran et al. performed a propensity-matched analysis showing for the first time that following resection for lung cancer, survival was significantly higher in patients with a BMI $\geq 30$ compared with those with BMI $<30$ [29].

To the best of our knowledge, this is the largest study that has demonstrated a positive association between BMI and survival in NSCLC. There are several explanations as to how obesity is associated with survival benefit, including genetic, endocrine, and nutritional components. Brennen et al. recently reported that one allele of the fat mass and obesity-associated (FTO) gene, which has been linked with increased BMI, was associated with a decreased risk of lung cancer [30]. The mechanism for this protective effect, however, is not clear [30].

Adipose tissue is considered an active and functional endocrine organ that may play a central role in explaining why obesity is protective in NSCLC. Abdul-Ghafar et al. demonstrated that expression of Adiponectin Receptor 1 (adipo R1) is indicative of a favorable prognosis in NSCLC [11]. Adiponectin may have a protective role in carcinogenesis as it has anti-angiogenic [31], anti-proliferative [32], proapoptotic effects, and also arrests cell growth [33] [34].

Females have lower incidence and higher survival rates in NSCLC when compared with males across all races [35]. It seems reasonable to hypothesize that females might have improved outcomes because of a protective effect from hormones such as estrogen. In fact, a recent retrospective analysis conducted by Katcoff et al. showed that the combination of estrogen plus progesterone plus the use of long term hormone therapy were associated with significant improvements in women with NSCLC [36]. Like women, obese individuals have higher levels of estrogens which might play a role in increased survival in NSCLC.

Consumption of phytochemicals and antioxidant-rich foods, such as fruit and vegetables, has a known protective effect on lung cancer risk [37]; accordingly, this protection may also be afforded to those with a diagnosis of NSCLC. It could therefore be hypothesized that obese individuals have higher intake of fruits and vegetables (or other unknown protective compounds) as a result of increased overall food intake and portion sizes thereby receiving more protective nutrients than those with a smaller total dietary intake.

Nutritional reserve may provide some explanation as to why obesity is protective in NSCLC survival. Cachexia which is commonly seen in NSCLC may not be as devastating in obese individuals because there is an ample energy supply in adipose tissue and supporting musculature of obese individuals. This may not provide an adequate explanation, however, given that increased body weight was associated with increased death rates for all cancers combined and for cancers at multiple specific sites [6].

In our study obese patients had 31.5\% localized presentations compared with $21.9 \%$ in non-obese and $17.1 \%$ of cachectic patients. $31.8 \%$ of obese patients had distant disease vs. $41.4 \%$ of non-obese patients and $47.3 \%$ of cachectic patients which would give this cohort of obese patients a survival advantage. Furthermore $40.3 \%$ of obese patients received surgery vs. $30.4 \%$ of non-obese and $20.8 \%$ of cachectic patients. Given that surgery is a curative modality this could increase the survival of the obese patients compared to non-obese patients. However, our multivariate regression analyses included variables for both stage at diagnoses and treatment; therefore, our adjusted results controlled for these confounders. Therefore, additional non-measured clinical or treatment factors, e.g., quality of the surgery, would need to be at work for these type of factors to play a role in survival. Interestingly, the fact that obese patients present with more limited disease and less distant disease than nonobese and cachectic patients may represent a distinct less aggressive biologic entity.

We acknowledge some potential limitations in our study. Most notable was the usage of ICD-9 coding to identify the obesity status of patients. The inability to utilize actual height and weight data could have caused variability in the three categories: obese, non-obese, cachexia. However, this is a limitation of using a population-based cancer registry that is difficult to overcome.

On the other hand, our study presented a number of advantages. First, it included a large sample size $(\mathrm{n}=$ 87,631) which is important in providing adequate power to detect significant differences even when performing subgroup analysis by smoking status and obesity (Figure 1). Second, the broad time span from 1996-2007 plus 3 years of follow up time allowed adequate years to perform survival analysis (Figure 1). Third, we were able to control for many clinical and demographic factors, and comorbidities, thus minimizing many potential confounding variables. Fourth, we were able to include a "cachexia” arm with a significant number of patients (n = 4,175 ) which eliminated possible confounder of this subgroup on the non-obese population survival statistics. Last, we included only NSCLC patients whereas many previous studies combined both small-cell lung cancer 
and NSCLC which are different disease entities.

\section{Conclusion}

Obese individuals with NSCLC survived longer than non-obese and cachectic patients. As expected, current or former smokers had worse survival compared to never smokers. Obesity may have a protective effect and provide a survival advantage. Further investigation to determine the mechanism of this benefit, i.e., hormonal, metabolic, nutrition-related, is warranted. Alternately obesity may merely be an indicator of less advanced and/or less aggressive disease.

\section{Acknowledgements}

This work was supported by the James \& Esther King Florida Biomedical Research Program (Grant 10KG-06).

\section{Prior Presentation}

Presented at ASCO 2015 annual meeting in a general poster session.

\section{Disclaimers}

An abstract for this research was originally published in the Journal of Clinical Oncology; J ClinOncol 33, 2015 (suppl; abstr 7534) in conjunction with the ASCO 2015 annual meeting $(\odot)$ Journal of Clinical Oncology.

\section{References}

[1] Jemal, A., Bray, F., Center, M.M., et al. (2011) Global Cancer Statistics. CA: A Cancer Journal for Clinicians, 61, 6990. http://dx.doi.org/10.3322/caac.20107

[2] Darby, S., Hill, D., Auvinen, A., et al. (2005) Radon in Homes and Risk of Lung Cancer: Collaborative Analysis of Individual Data from 13 European Case-Control Studies. British Medical Journal, 330, 223. http://dx.doi.org/10.1136/bmj.38308.477650.63

[3] Van Loon, A.J., Kant, I.J., Swaen, G.M., et al. (1997) Occupational Exposure to Carcinogens and Risk of Lung Cancer: Results from The Netherlands Cohort Study. Occupational and Environmental Medicine, 54, 817. http://dx.doi.org/10.1136/oem.54.11.817

[4] Tanvetyanon, T. and Bepler, G. (2008) Beta-Carotene in Multivitamins and the Possible Risk of Lung Cancer among Smokers versus Former Smokers: A Meta-Analysis and Evaluation of National Brands. Cancer, 113, 150-157. http://dx.doi.org/10.1002/cncr.23527

[5] Biesalski, H.K., Bueno de Mesquita, B., Chesson, A., Chytil, F., Grimble, R., Hermus, R.J., Kohrle, J., Lotan, R., Norpoth, K., Pastorino, U. and Thurnham, D. (1998) European Consensus Statement on Lung Cancer: Risk Factors and Prevention. Lung Cancer Panel. CA: A Cancer Journal for Clinicians, 48, 167-176. http://dx.doi.org/10.3322/canjclin.48.3.167

[6] Calle, E.E., Rodriguez, C., Walker-Thurmond, K. and Thun, M.J. (2003) Overweight, Obesity, and Mortality from Cancer in a Prospectively Studied Cohort of US Adults. The New England Journal of Medicine, 348, 1625-1638. http://dx.doi.org/10.1056/NEJMoa021423

[7] Bryant, A. and James, R. (2007) Differences in Epidemiology, Histology, and Survival between Cigarette Smokers and Never-Smokers Who Develop Non-small Cell Lung Cancer. Chest, 132, 185-192. http://dx.doi.org/10.1378/chest.07-0442

[8] Siegel, R., Naishadham, D. and Jemal, A. (2013) Cancer Statistics, 2013. CA: A Cancer Journal for Clinicians, 63, 1130. http://dx.doi.org/10.3322/caac.21166

[9] US Department of Health, Education, and Welfare (1964) Smoking and Health: Report of the Advisory Committee to the Surgeon General of the Public Health Service. US Department of Health, Education, and Welfare, Public Health Service, Center for Disease Control, Washington DC, PHS Publication No. 1103.

[10] Calle, E.E. and Kaaks, R. (2004) Overweight Obesity and Cancer: Epidemiological Evidence and Proposed Mechanism. Nature Reviews Cancer, 4, 579-591. http://dx.doi.org/10.1038/nrc1408

[11] Abdul-Ghafar, J., et al. (2013) Expression of Adiponectin Receptor 1 Is Indicative of Favorable Prognosis in NonSmall Cell Lung Carcinoma. The Tohoku Journal of Experimental Medicine, 229, 153-162. http://dx.doi.org/10.1620/tjem.229.153 
[12] Nomura, A., Heilbrun, L.K. and Stemmermann, G.N. (1985) Body-Mass Index as a Predictor of Cancer in Men. Journal of the National Cancer Institute, 74, 319-323.

[13] Knekt, P., Heliovaara, M., Rissanen, A., Aromaa, A., Seppanen, R., Teppo, L. and Pukkala, E. (1991) Leanness and Lung-Cancer Risk. International Journal of Cancer, 49, 208-213. http://dx.doi.org/10.1002/ijc.2910490211

[14] Kabat, G.C. and Wynder, E.L. (1992) Body Mass Index and Lung Cancer Risk. American Journal of Epidemiology, 135, 769-774.

[15] Goodman, M.T. and Wilkens, L.R. (1993) Relation of Body Size and the Risk of Lung Cancer. Nutrition and Cancer, 20, 179-186. http://dx.doi.org/10.1080/01635589309514284

[16] Chyou, P.H., Nomura, A.M.Y. and Stemmermann, G.N. (1994) A Prospective-Study of Weight, Body Mass Index and Other Anthropometric Measurements in Relation to Site-Specific Cancers. International Journal of Cancer, 57, 313317. http://dx.doi.org/10.1002/ijc.2910570304

[17] Olson, J.E., Yang, P., Schmitz, K., Vierkant, R.A., Cerhan, J.R. and Sellers, T.A. (2002) Differential Association of Body Mass Index and Fat Distribution with Three Major Histologic Types of Lung Cancer: Evidence From a Cohort of Older Women. American Journal of Epidemiology, 156, 606-615. http://dx.doi.org/10.1093/aje/kwf084

[18] Kubik, A.K., Zatloukal, P., Tomasek, L., Pauk, N., Havel, L., Krepela, E. and Petruzelka, L. (2004) Dietary Habits and Lung Cancer Risk among Non-Smoking Women. European Journal of Cancer Prevention, 13, 471-480. http://dx.doi.org/10.1097/00008469-200412000-00002

[19] Samanic, C., Chow, W.H., Gridley, G., Jarvholm, B. and Fraumeni Jr., J.F. (2006) Relation of Body Mass Index to Cancer Risk in 362,552 Swedish Men. Cancer Causes \& Control, 17, 901-909. http://dx.doi.org/10.1007/s10552-006-0023-9

[20] Liu, E., Wang, X., Yuan, J. and Gao, Y. (2004) Association of Body Mass Index with Risk of Lung Cancer: Evidence from a Middle Aged Male Cohort in Shanghai, China. Chinese Journal of Clinical Oncology, 1, 90-95. http://dx.doi.org/10.1007/BF02759454

[21] Reeves, G.K., Pirie, K., Beral, V., Green, J., Spencer, E. and Bull, D. (2007) Cancer Incidence and Mortality in Relation to Body Mass Index in the Million Women Study: Cohort Study. BMJ, 335, 1134-1139. http://dx.doi.org/10.1136/bmj.39367.495995.AE

[22] Kanashiki, A., Sairenchi, T., Saito, Y., Ishikawa, H., Satoh, H. and Sekizawa, K. (2005) Body Mass Index and Lung Cancer: A Case-Control Study of Subjects Participating in a Mass-Screening Program. Chest, 128, 1490-1496. http://dx.doi.org/10.1378/chest.128.3.1490

[23] Lee, I.M. and Paffenbarger Jr., R.S. (1992) Re: “Body Mass Index and Lung Cancer Risk”. American Journal of Epidemiology, 136, 1417-1419.

[24] Chen, Z., Yang, G., Offer, A., Zhou, M., Smith, M., Peto, R., Ge, H., Yang, L. and Whitlock, G. (2012) Body Mass Index and Mortality in China: A 15-Year Prospective Study of 220000 Men. International Journal of Epidemiology, 41, 472-481. http://dx.doi.org/10.1093/ije/dyr208

[25] Kabat, G.C., Miller, A.B. and Rohan, T.E. (2007) Body Mass Index and Lung Cancer Risk in Women. Epidemiology, 18, 607-612. http://dx.doi.org/10.1097/EDE.0b013e31812713d1

[26] Rauscher, G.H., Mayne, S.T. and Janerich, D.T. (2000) Relation between Body Mass Index and Lung Cancer Risk in Men and Women Never and Former Smokers. American Journal of Epidemiology, 152, 506-513. http://dx.doi.org/10.1093/aje/152.6.506

[27] Yang, Y., Dong, J., Sun, K., Zhao, L., Zhao, F., Wang, L. and Jiao, Y. (2012) Obesity and Incidence of Lung Cancer: A Meta-Analysis. International Journal of Cancer, 132, 1162-1169. http://dx.doi.org/10.1002/ijc.27719

[28] El-Zein, M., Parent, M. and Rousseau, M. (2013) Comments on a Recent Meta-Analysis: Obesity and Lung Cancer. International Journal of Cancer, 132, 1962-1963. http://dx.doi.org/10.1002/ijc.27854

[29] Attaran, S., McShane, J., Whittle, I., Poullis, M. and Shackcloth, M. (2012) A Propensity-Matched Comparison of Survival after Lung Resection in Patients with a High versus Low Body Mass Index. European Journal of Cardio-Thoracic Surgery, 42, 653-658. http://dx.doi.org/10.1093/ejcts/ezs135

[30] Brennan, P., McKay, J., Moore, L., Zaridze, D., Mukeria, A., Szeszenia-Dabrowska, N., Lissowska, J., Rudnai, P., Fabianova, E., Mates, D., Bencko, V., Foretova, L., Janout, V., Chow, W.H., Rothman, N., Chabrier, A., Gaborieau, V., Timpson, N., Hung, R.J. and Smith, G.D. (2009) Obesity and Cancer: Mendelian Randomization Approach Utilizing the FTO Genotype. International Journal of Epidemiology, 38, 971-975. http://dx.doi.org/10.1093/ije/dyp162

[31] Molica, S., Digiesi, G., Vacca, A., Mirabelli, R., Todoerti, K., Battaglia, C., Morabito, F., Neri, A. and Ribatti, D. (2009) Does Adiponectin Act as an Antiangiogenic Factor in B-Cell Chronic Lymphocytic Leukemia? Advances in Hematology, 2009, Article ID: 287974. http://dx.doi.org/10.1155/2009/287974

[32] Dos Santos, E., Benaitreau, D., Dieudonne, M.N., Leneveu, M.C., Serazin, V., Giudicelli, Y. and Pecquery, R. (2008) 
Adiponectin Mediates an Antiproliferative Response in Human MDA-MB 231 Breast Cancer Cells. Oncology Reports, 20, 971-977.

[33] Kang, J.H., Lee, Y.Y., Yu, B.Y., Yang, B.S., Cho, K.H., Yoon, D.K. and Roh, Y.K. (2005) Adiponectin Induces Growth Arrest and Apoptosis of MDA-MB-231 Breast Cancer Cell. Archives of Pharmacal Research, 28, 1263-1269. http://dx.doi.org/10.1007/BF02978210

[34] Cong, L., Gasser, J., Zhao, J., Yang, B., Li, F. and Zhao, A.Z. (2007) Human Adiponectin Inhibits Cell Growth and Induces Apoptosis in Human Endometrial Carcinoma Cells, HEC-1-A and RL95-2. Endocrine-Related Cancer, 14, 713-720. http://dx.doi.org/10.1677/ERC-07-0065

[35] Howlaner, N., Noone, A., Krapcho, M., et al. (2012) Seer Cancer Statistics Review, 1975-2009 (Vintage 2009 Populations). Based on November 2011 SEER Data Submission, National Cancer Institute, Bethesda.

[36] Katcoff, H., Wenzlaff, S.A. and Schwartz, A.G. (2014) Survival in Women with NSCLC: The Role of Reproductive History and Hormone Use. Journal of Thoracic Oncology, 9, 355-361. http://dx.doi.org/10.1097/jto.0000000000000077

[37] Koutsokera, A., Kiagia, M., Saif, M.K., Souliotis, K. and Syrigos, K.N. (2013) Nutrition Habits, Physical Activity, and Lung Cancer: An Authoritative Review. Clinical Lung Cancer, 14, 342-350. 